\title{
The Sstl polymorphism of the apo $C$-III gene is associated with insulin sensitivity in young men
}

\author{
F. Pérez-Jiménez, J. López-Miranda, P. Gómez, M. J. Velasco, C. Marín, P. Pérez-Martínez, \\ J. A. Moreno, J. A. Paniagua \\ The Lipid and Arteriosclerosis Research Unit, Reina Sofia University Hospital, Medical School, University of Cordoba, Spain
}

\begin{abstract}
Aims/hypothesis. Insulin resistance is considered to be a risk factor for diabetes and coronary heart disease and is determined by the interaction between genetic and environmental factors. The SstI polymorphism in the apolipoprotein $C$-III gene has been related to the presence of different features of the insulin resistance syndrome. We investigate if this mutation influences the peripheral effect of insulin in healthy young subjects (30 men and 29 women) eating a westernised diet.

Methods. We investigated peripheral insulin sensitivity with the insulin suppression test after a 28-day west-
\end{abstract}

ernised high-saturated fat diet (38\% total fat and 18\% saturated fat with $115 \mathrm{mg}$ of cholesterol per $1000 \mathrm{Ju}$ ). Results. Steady state plasma glucose values were lower in $S 1-S 1$ compared with $S 1-S 2$ men ( $p=0.018$ by ANOVA), but not in women ( $p=0.723)$.

Conclusion/interpretation. There was no difference between carriers and non-carriers of the $S 2$ allele in relation to incidence and sensitivity; although on subgroup analysis there was an effect in men but not in women. [Diabetologia (2002) 45:1196-1200]

Keywords High-saturated fat diet, insulin sensitivity, glucose metabolism, non-esterified fatty acids.
Insulin resistance is considered to be a risk factor for both diabetes and coronary heart disease and is determined by the interaction between genetic and environmental factors. In general, high intake of dietary fat has been associated with obesity and its co-morbid conditions, including heart disease and diabetes. All of these factors are related to the global process of the "westernisation" of lifestyles and dietary habits, especially the high intake of calories from saturated fat. Insulin resistance usually precedes the diagnosis of

Received: 4 January 2002 / Revised: 12 April 2002

Published online: 19 June 2002

(C) Springer-Verlag 2002

Corresponding author: F. Pérez-Jiménez, MD, PhD, Unidad de Lípidos y Arteriosclerosis, Hospital Universitario Reina Sofía. Avda Menéndez Pidal, s/n. 14004, Córdoba, Spain. E-mail: fperez@hrs.sas.junta-andalucia.es

Abbreviations: HDL-C, HDL-cholesterol; LDL-C, LDL-cholesterol; SFA diet, enriched in saturated fatty acids diet; SSPG, steady state plasma glucose; SSPI, steady state plasma insulin; USDA, United States Department of Agriculture.
Type II (non-insulin-dependent) diabetes mellitus by decades. In most cases, the clinical expression of the disease can be prevented by dietary and lifestyle modification [1]. On the other hand, the genetic base of Type II diabetes is very heterogeneous and has been related to various genetic mutations that codify proteins linked to glucose and insulin metabolism, such as the insulin receptor [2], the insulin receptor substrate-1 [3], the Rad protein [4], the glycogen synthase [5] and the $\beta$-3-adrenergic receptor [6]. However, the genetic background of insulin resistance and Type II diabetes is more complex and it can also involve other genes seemingly unrelated to carbohydrate metabolism.

Apo C-III is an important component of lipoprotein metabolism and is involved in the delipidation of triglyceride rich particles [7, 8]. The $S 2$ allele, identified by the restriction enzyme Sst-I, is in disequilibrium with two mutations located in the promoter region of the apo C-III gene [9]. The presence of this polymorphism has been associated with clinical and biochemical characteristics of the insulin-resistance state [10], 
including an increase in insulin plasma concentrations after an oral-glucose-tolerance test in healthy men [11]. Our aim is to investigate the influence of the Sst-I polymorphism in the apo C-III gene on insulin sensitivity in healthy young men and women after they ingest a westernised diet enriched in saturated fat.

\section{Subjects and methods}

Subjects and diets. Fifty-nine healthy normolipemic (total plasma cholesterol concentrations lower than $5.3 \mathrm{mmol} / \mathrm{l}$ ) subjects (30 men and 29 women) attending the University of Cordoba volunteered to participate in the study. The subjects were selected from among 300 hundred healthy young men and women; 37 had the genotype S1-S1 (16 men and 21 women) and 22 had the genotype $S 1-S 2$ (14 men and 8 women). All subjects gave their informed consent according to the Declaration of Helsinki as revised in 1996. All underwent a comprehensive medical history, a physical examination and clinical chemistry analyses before enrolment. Subjects were younger than 30 years of age (mean age 23.1 $\pm 1.8 \mathrm{SD}$ ) and showed no evidence of any chronic illness (hepatic, renal, thyroid, or cardiac dysfunction) or unusually high levels of physical activity.

Dietary information, including alcohol consumption, was collected during 7 consecutive days. Individual energy requirements were calculated by taking into consideration subject's weight and physical activity. Subjects were encouraged to maintain their regular physical activity and lifestyle and were asked to record any event that could affect the outcome of the study, such as stress, change in smoking habits, and alcohol consumption or foods not included in the experimental design.

The study design included a 28-day period during which all the subjects consumed a high-saturated fat-enriched diet (SFA diet), with $15 \%$ of energy as protein, $47 \%$ as carbohydrates and $38 \%$ as fat $(20 \%$ SFA fat, $12 \%$ monounsaturated fat and $6 \%$ polyunsaturated fat). The mean dietary cholesterol intake was $27 \mathrm{mg} / \mathrm{MJ}$. A glucose suppression test was carried out at the end of the dietary intervention. The Human Investigation Review Committee at the Reina Sofia University Hospital approved the study.

The composition of the experimental diet was calculated using the United States Department of Agriculture (USDA) food tables [12] or the Spanish food composition tables for local foodstuffs [13]. Fourteen menus, prepared with regular solid foods, were rotated during the experimental period. Palm oil and butter was used to provide SFA fat. Lunch and dinner were consumed in the hospital dining room, whereas breakfast and an afternoon coffee break were taken in the medical school cafeteria. A dietician supervised all meals. Duplicate samples from each menu were collected, homogenized, and stored at $-80^{\circ} \mathrm{C}$. Protein, fat and $\mathrm{CHO}$ content of the diet were analysed using standard methods [14].

Blood sampling and biochemical determinations. Venous blood samples for glucose, lipid and lipoprotein analysis were collected in EDTA containing tubes from subjects after a 12-h overnight fast. Cholesterol and triglycerides were assayed by enzymatic procedures. HDL-cholesterol was measured by analysing the supernatant obtained after precipitation of a plasma aliquot with extra sulphate- $\mathrm{Mg}^{2+}$. The LDL-cholesterol concentration was calculated from the total cholesterol, triglycerides, and HDL-cholesterol values using the Friedewald formula [15]. Non-esterified free fatty acid concentrations were analysed by an enzymatic colorimetric assay (Boehringer Mannheim, Mannheim, Germany) [16]. To reduce interassay variation, plasma for biochemical determinations were stored at $-80^{\circ} \mathrm{C}$ and analysed in duplicate at the end of the study.

Glucose suppression test. A modified insulin suppression test $[17,18]$ was carried out on all the subjects at the end of the dietary period. The study began at 8:00 am, after $12 \mathrm{~h}$ of fasting. A continuous infusion of somatostatin $(214 \mathrm{nmol} / \mathrm{h})$, insulin $\left(180 \mathrm{pmol} \cdot \mathrm{m}^{-2} \cdot \mathrm{min}^{-1}\right)$ and glucose $\left(13.2 \mathrm{mmol} \cdot \mathrm{m}^{-2} \cdot \mathrm{min}^{-1}\right)$ were infused in the same vein. Somatostatin was used to inhibit endogenous insulin secretion. Blood was sampled every $30 \mathrm{~min}$ for the first $2.5 \mathrm{~h}$, by which time steady-state plasma glucose (SSPG) and steady-state plasma insulin (SSPI) concentrations were achieved. Blood was then sampled at 10-min intervals for the last $30 \mathrm{~min}$ (at minutes 150, 160, 170 and 180) for measurement of plasma glucose and insulin concentrations. These four values determined the SSPG and SSPI concentrations. Since SSPI concentrations were similar in all subjects, SSPG concentrations provided a measure of the ability of insulin to promote the disposal of infused glucose. Subjects with high SSPG are relatively more insulin resistant than others with lower SSPG.

Determination of the apo C-III genotype. DNA was extracted from $10 \mathrm{ml}$ of peripheral venous blood in EDTA $(1 \mathrm{mg} / \mathrm{ml})$ containing tubes by the salting-out method. The apo $C$-III polymorphism was determined by PCR amplification of a fragment of 428-bp of the apo C-III gene using $250 \mathrm{ng}$ of genomic DNA, $0.2 \mu \mathrm{mol}$ of nucleotides, $2.5 \mathrm{U}$ of Taq polymerase (Promega, Madison, Wis., USA) and $1 \mu \mathrm{mol} / \mathrm{l}$ of each "primer" (CIII-1, 5'-GGTGACCGATGGCTTCAGTT-3'; CIII-2, 5'-CAGAAGGTGGATAGAGCGCT-3') in a final volume of $50 \mu \mathrm{l}$. DNA was denatured at $95^{\circ} \mathrm{C}$ for 5 min followed by 30 cycles of denaturation at $95^{\circ} \mathrm{C}$ a minute, "annealing" at $55^{\circ} \mathrm{C}$ for $2 \mathrm{~min}$, and extension at $72^{\circ} \mathrm{C}$ for $1.5 \mathrm{~min}$. Twenty $\mu \mathrm{l}$ of the PCR amplification products were digested with 10 units of Sst-1 restriction enzyme in a total volume of $35 \mu \mathrm{l}$. The products obtained were submitted to $8 \%$ non-denaturing polyacrylamide electrophoresis at $150 \mathrm{~V}$ for $2 \mathrm{~h}$ followed by silver staining.

Statistical analyses. Statistical analyses were carried out using the SPSS statistical package. ANOVA for repeated measures was used to analyse the differences between SSPG and SSPI concentrations among several study groups. When statistically significant effects were demonstrated, Tukey's post-hoc test was used to identify differences between groups. The KolmogorovSmirnov one-sample test was used to test the normality of the distribution. Variables that were not normally distributed were log-transformed before the analysis. A $p$ value of less than 0.05 was considered significant. All data are presented in the text and tables as means $\pm \mathrm{SD}$.

\section{Results}

There were no significant differences between subjects with the S1S1 genotype $(n=37)$ and those with the $S 1 S 2$ genotype $(n=22)$ for any of the lipid parameters, fasting glucose plasma concentrations or fasting NEFA after the SFA diet (Table 1). The absence of significant differences in most parameters of the study was observed when we compared men and women with the different genotypes (Table 2). However, fast- 
Table 1. Characteristics according to apo C-III genotype during a high saturated fat diet

\begin{tabular}{llll}
\hline & S1S1 $(36)$ & S1S2 $(23)$ & $\mathrm{P}^{\mathrm{a}}$ \\
\hline Age (years) & $22.3 \pm 10.9$ & $22.9 \pm 10.9$ & 0.339 \\
BMI (Kg/m $\left.{ }^{2}\right)$ & $21.3 \pm 3.00$ & $22.2 \pm 3.12$ & 0.189 \\
Total cholesterol (mmol/l) & $4.13 \pm 0.61$ & $4.33 \pm 0.59$ & 0.228 \\
Triglycerides (mmol/l) & $0.67 \pm 0.24$ & $0.78 \pm 0.36$ & 0.180 \\
LDL-C (mmol/l) & $2.53 \pm 0.54$ & $2.74 \pm 0.57$ & 0.156 \\
HDL-C (mmol/l) & $1.28 \pm 0.23$ & $1.21 \pm 0.34$ & 0.373 \\
Apo B (g/l) & $0.71 \pm 0.12$ & $0.77 \pm 0.13$ & 0.111 \\
Apo AI (g/l) & $1.49 \pm 0.16$ & $1.48 \pm 0.17$ & 0.885 \\
Fasting glucose (mmol/l) & $4.78 \pm 0.35$ & $4.91 \pm 0.31$ & 0.101 \\
Fasting NEFA (mmol/l) & $0.44 \pm 0.25$ & $0.61 \pm 0.26$ & 0.098 \\
\hline
\end{tabular}

a ANOVA

Values are given as means $\pm \mathrm{SD}$

ing NEFA concentrations were higher during the highSFA diet in S1-S2 men compared with S1-S1 men.

Insulin values during the SSPI period (means \pm SD at minutes $150,160,170$ and 180 of the insulin suppression test) were similar in S1-S1 men and women (mean values \pm SD for the four samples were 9.5 \pm 2.8 and $9.8 \pm 2.3 \mathrm{mIU} / \mathrm{ml}$, respectively), and $S 1-S 2$ men and women (mean values \pm SD 9.8 \pm 2.2 and $9.4 \pm 2.8$ $\mathrm{mIU} / \mathrm{ml}$, respectively). During the SSPG, no significant differences were observed between the SI-SI and the $S 1-S 2$ subjects (Fig. $1 \mathrm{~A} ; p=0.101$ by ANOVA) or between the S1-S1 women compared with S1-S2 women (Fig. 1B; $p=0.723$ ). These data indicate the absence of a polymorphism effect on the whole population and on the subgroup of women. However, the $S 2$ allele in the apo $C$-III gene was associated with a relevant decrease in insulin sensitivity in men (Fig. 1C; $p=0.018$ ).

\section{Discussion}

Our data indicate that the presence of the $S 2$ allele of the Sst-I polymorphism in the apo C-III gene is associated with a decrease in peripheral insulin action assessed by the insulin suppression test in healthy men after ingesting a westernised diet. The same effect was not observed in women. The insulin suppression test was done at the end of the dietary period and not at the beginning; thus the possible effect of variation between subjects cannot be completely excluded.

Currently, the mechanism by which this genetic variation can influence $\mathrm{CHO}$ metabolism is not known. Insulin acts upon the promoter of the apo $C$-III gene, reducing its expression and plasma concentrations of the apoprotein. In contrast, the $S 2$ allele, identified by the restriction enzyme Sst-I, is in disequilibrium with two mutations located in the promoter region of the apo C-III gene [9]. The presence of these two mutations determines the absence of regulation by the insu-
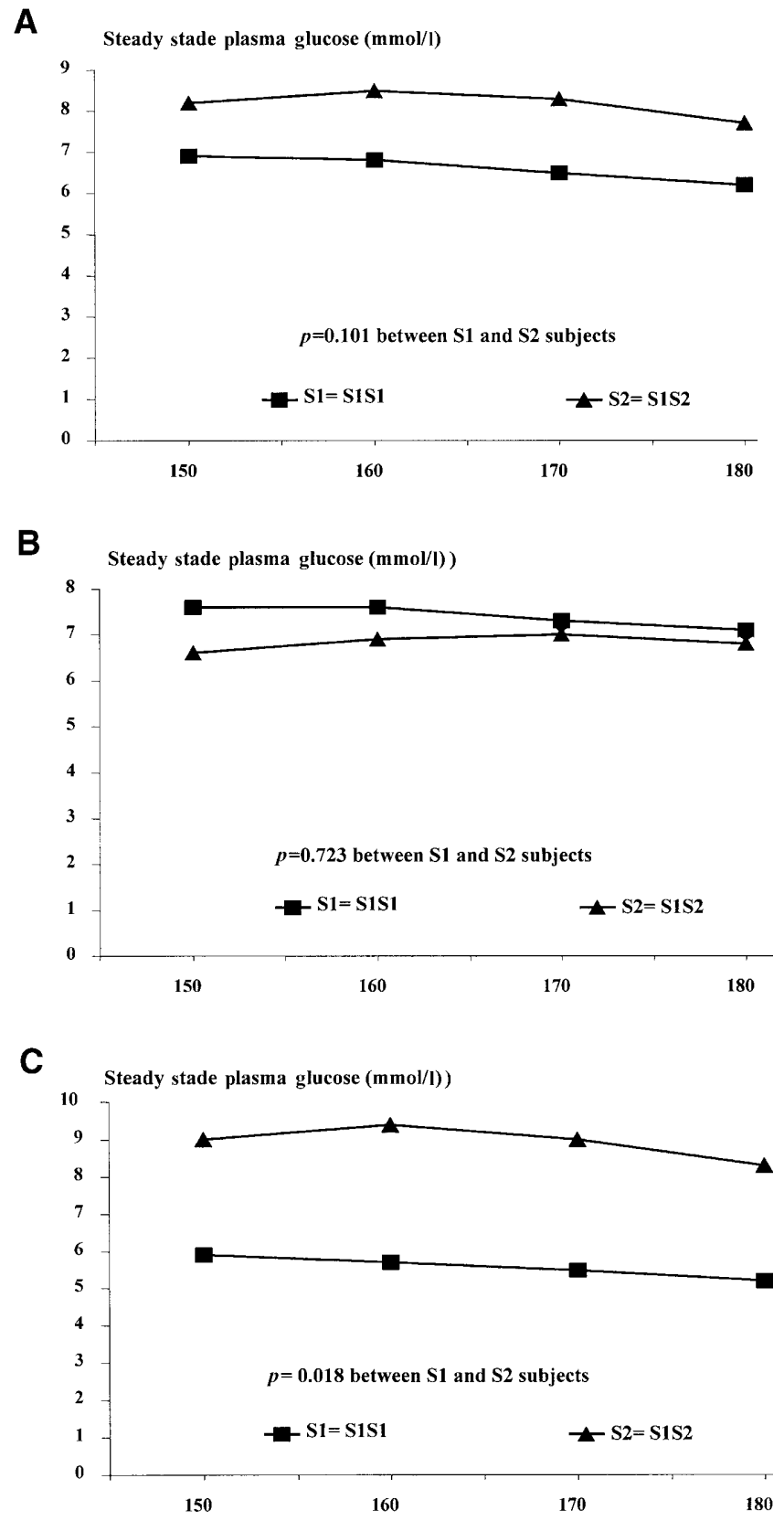

Fig. 1. Line graphs showing steady state plasma glucose concentration during the insulin suppression test, during a SFA diet, in total population (A), women (B) and men (C)

lin and the decrease of apo-CIII, which is physiologically produced by the hormone, resulting in an increase in plasma concentrations of apoprotein CIII [19]. Apo C-III modulates the metabolism of triglyceride rich particles [20], so its overexpression could interfere in the plasmatic clearance of the triglyceride rich lipoproteins, resulting in its subsequent increase. Furthermore, it has been suggested that hypertriglyceridaemia and an SFA diet might favour insulin resistance $[21,22,23]$ by increasing plasma concentrations of NEFA, which could inhibit glucose utilisation by peripheral cells and reduce the effect of peripheral insulin [24]. 
Table 2. Characteristics of men and women with S1S1 and S1S2 genotypes during a high saturated fat diet

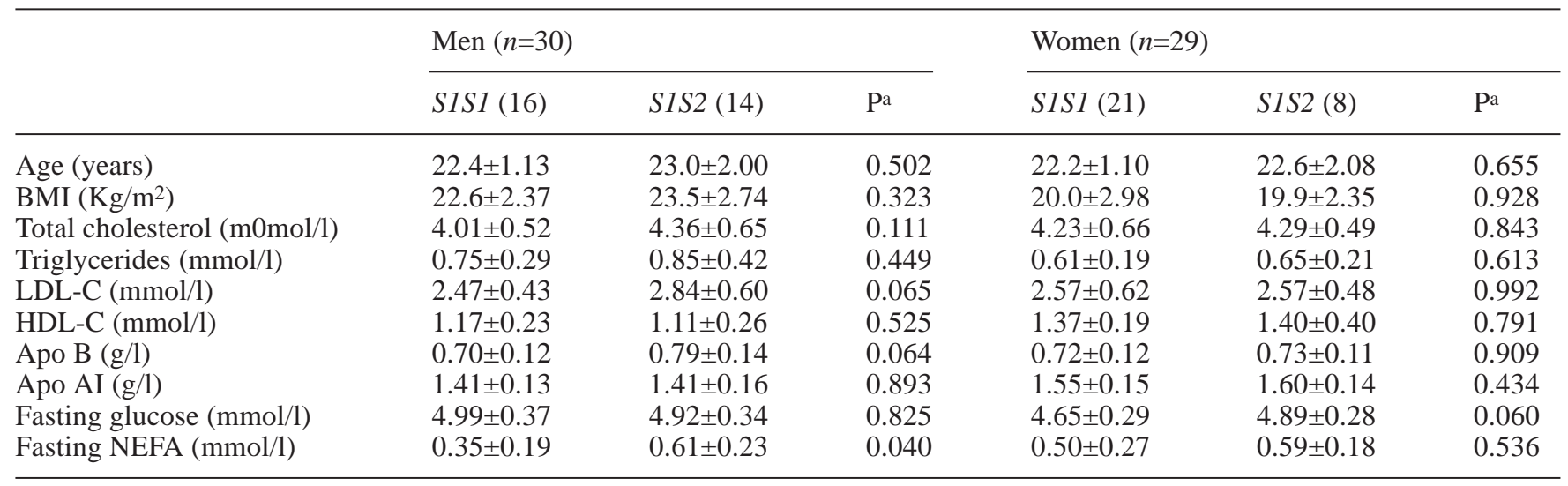

a ANOVA; Values are given as means \pm SD

In this study no significant associations between the $S 2$ allele and plasma lipid variables in men and women were found. However, these findings were not supported by other investigators $[25,26]$ who found differences between and women in the association of Sst-I polymorphism with lipids. A study [27] described an increase of total cholesterol in both male and female carriers of the $S 2$ allele, whereas an increase in plasma apo B levels and a trend toward lower HDL-C concentrations was noted only in $S 2$ male carriers. Discrepancies with our results could be due to three factors: (i) the subjects in our study were young, healthy and normolipaemic; (ii) there were no hypercholesterolaemic or hypertriglyceridaemic subjects; (iii) the size of the sample was small and was calculated to study insulin resistance and not lipid parameters. Other studies $[28,29]$ carried out in isolated communities analysed men and women separately but they also failed to show any association of the allele with variations in the lipid profile.

In agreement with our results, another study [25] found that the $S 2$ allele of the Sst-I polymorphism in the apo $C$-III gene was associated with increased fasting insulin concentrations in men but not in women. The lack of effect of the $S 2$ allele on insulin sensitivity in females is similar to the phenomenon observed upon plasma lipids in response to changes in diet in the presence of different apo E polymorphisms [30]. This effect could be caused by a protective effect of the hormonal status to environmental changes [25]. Female hormones are thought to intervene by either inhibiting the greater expression of apo $C$-III derived from the presence of the $S 2$ allele or by interfering in the release of NEFA to the plasma with a subsequent increase in glycaemia via the Randle cycle [31].

In conclusion, there was no difference between carriers and noncarriers of the $S 2$ allele in relation to insulin sensitivity. However on subgroup analysis there was an effect in men, but not in women. This finding suggests that $S 2-S 1$ men have a high risk of developing insulin resistance syndrome and Type II diabetes melli- tus under a high-saturated fat enriched diet. Therefore, a possible strategy for the prevention of cardiovascular disease would be to identify this population.

Acknowledgements. This work was supported by research grants from the CICYT (SAF96/0060, OLI 96/2146 to F. Pérez-Jiménez), the Spanish Ministry of Health (FIS 96/1540, 98/1531, 01/0449 and to J. López-Miranda, FIS 99/0949 to F. Pérez-Jiménez), Fundación Cultural "Hospital Reina SofíaCajasur" (to C. Marín and P. Gómez), Consejería de Salud, Servicio Andaluz de Salud (PAI 97/58, 98/126, 99/116 and 00/212, PAI 97/57, 98/132, 99/165 and 00/39 to F. Pérez-Jiménez), Consejería de Agricultura y Pesca de la Junta de Andalucía, Patrimonio Comunal Olivarero (to F. Pérez-Jiménez). We would also like to thank J. M. Ordovas for his excellent critical revision of our manuscript and E. Paz Rojas for his excellent technical assistance.

\section{References}

1. Mayer-Davis EJ, Monaco JH, Hoen HM et al. (1997) Dietary fat and insulin sensitivity in a triethnic population: the role of obesity. The Insulin Resistance Atherosclerosis Study (IRAS). Am J Clin Nutr 67:79-87

2. Kusari J, Verma US, Buse JB (1991) Analysis of the gene sequences of the insulin receptor and the insulin-sensitive glucose transporter (GLUT-4) in patients with common type non-insulin-dependent diabetes mellitus. J Clin Invest 88:1323-1330

3. Almind K, Bjorbaek C,Vestergaard H, Hansen T, Echwald SM, Pedersen O (1993) Aminoacid polymorphisms of insulin receptor substrate-1 in non-insulindependent diabetes mellitus. Lancet 342:828-832

4. Reynet C, Kahn CR (1993) Rad: a member of the Ras family overexpressed in muscle of type II diabetic human. Science 262:1441-1444

5. Bjorbaek C, Echwald SM, Hubricht P et al. (1994) Genetic variants in promoters and coding region of the muscle glycogen synthase and the insulin-responsive GLUT-4 genes in NIDDM. Diabetes 43:976-983

6. Walston J, Silver K, Bogardus C et al. (1995) Time of onset of non-insulin dependent diabetes mellitus and genetic variation in the $\beta 3$-adrenergic-receptor gen. N Engl J Med 333:343-347

7. McConathy WJ, Gesquiere JC, Bass H, Tartar A, Fruchart JC, Wang CS (1992) Inhibition of lipoprotein 
lipase activity by synthetic peptides of apolipoprotein C-III. J Lipid Res 33:995-1003

8. Aalto-Setälä K, Fisher EA, Chen X et al. (1992) Mechanism of hypertriglyceridemia in human apolipoprotein (apo) C-III transgenic mice: diminished very low density lipoprotein fractional catabolic rate associated with increased apo C-III and reduced apo E on the particles. J Clin Invest 90:1889-1900

9. Dammerman M, Sandkuijl LA, Halaas JL, Chung B, Breslow JL (1993). An apolipoprotein CIII haplotype protective against hypertriglyceridemia is specified by promoter and $3^{\prime}$ untranslated region polymorphism. Proc Natl Acad Sci USA 90:4562-4566

10. Tas S, Abdella NA (1994) Blood pressure, coronary artery disease, and glycaemic control in type 2 diabetes mellitus: relation to apolipoprotein-C-III gene polymorphism. Lancet 343:1194-1195

11. Salas J, Jansen S, López-Miranda J et al. (1998) The SstI polymorphism of the apolipoprotein C-III gene determines the insulin response to an oral-glucose-tolerance test after consumption of a diet rich in saturated fats. Am J Clin Nutr 68:396-401

12. Human Nutrition Information Service Department of Agriculture (1987) Composition of foods. Agriculture handbook N1 8 US Government Printing Office, Washington DC

13. Varela G (1980) Food composition tables. Instituto de Nutrición CSIC, Madrid

14. Association of Official Analytical Chemists (1990) Official methods of analysis. 15th edn (modified). Association of Official Analytical Chemists, Arlington

15. Friedewald WT, Levy RI, Fredrickson DS (1972) Estimation of the concentration of low density lipoprotein cholesterol in plasma without use of preparative ultracentrifuge. Clin Chem 18:499-502

16. Shimizu S, Inoue K, Tani Y, Yamada H (1979) Enzymatic microdetermination of serum free fatty acids. Anal Biochem 98:341-345

17. Harano Y, Ohgaku S, Hidaka H et al. (1977) Glucose, insulin and somatostatin infusion for the determination of insulin sensitivity. J Clin Endocrinol Metab 45:11241127

18. Laws A, Jeppesen JL, Maheux PC et al. (1994) Resistance to insulin-stimulated glucose uptake and dyslipidemia in Asian Indian. Arterioscler Thromb 14:917-922

19. Li W, Dammerman M, Smith JD et al. (1995) Common genetic variation in the promoter of the human apo C-III gene abolishes regulation by insulin and may contribute to hypertriglyceridemia. J Clin Invest 96:2601-2605

20. Ginsbeg HN, Li NA, Goldberg IJ et al. (1986) Apolipoprotein B metabolism in subjects with deficiency of apolipo- proteins C-III and A-I. Evidence that apolipoprotein C-III inhibits catabolism of triglyceride-rich lipoproteins by lipoprotein lipase in vivo. J Clin Invest 78:1287-1295

21. Storlien LH, Pan DA, Kriketos AD, Baun LA (1993) High fat diet induces fat resistance. Lessons and implications from animal studies. Ann NY Acad Sci 683:82-90

22. Steiner G (1991) Altering triglyceride concentrations changes insulin-glucose relationships in hypertriglyceridemic patients. Diabetes Care 14:1077-1081

23. Pérez Jiménez F, López Miranda J, Pinillos MD et al. (2001) A Mediterranean and high-carbohydrate diet improve glucose metabolism in healthy young persons. Diabetologia 44:2038-2043

24. Bjontorp P (1994) Fatty acids, hyperinsulinemia, and insulin resistance: which comes first. Curr Opin Lipidol 5:166-174

25. Russo GT, Meigs JB, Cupples LA et al. (2001) Association of the Sst-I polymorphism at the APOC3 gene locus with variations in lipid levels, lipoprotein subclass profiles and coronary Heart disease risk: the Framingham offspring study. Atherosclerosis 158:173-181

26. Ordovas JM, Civeira F, Genest J Jr et al. (1991) Restriction fragment length polymorphisms of the apolipoproteina A-I, C-III, A-IV gene locus. Relationship with lipids, apolipoproteins and premature coronary artery disease. Atherosclerosis $87: 75-86$

27. Shoulders CC, Harry PJ, Lagrost L et al. (1991) Variation at the apo AI/CIII/AIV gene complex is associated with elevated plasma levels of ApoCIII. Atherosclerosis $87: 239-247$

28. Dallinga-Thie GM, Bu XD, van Linde-Sibenius Trip M et al. (1996) Apolipoprotein A-I/C-III/A-IV gene cluster in familial combined hyperlipidemia: effects ion LDL-cholesterol and apolipoproteins B and CIII. J Lipid Res 37:136147

29. Kessling A, Ouelette S, Bouffard O et al. (1991) Patterns of associations between genetic variability in apoliprotein (Apo) B, Apo AI-CIII-AIV, and cholesterol ester transfer protein gene regions and quantitative variation I lipid and lipoprotein traits: influence of gender and exogenous hormones. Am J Hum Genet 50:92-106

30. López-Miranda J, Ordovas JM, Mata P, Lichtenstein AH, Clevidence B, Judd JT (1994) Effect of apolipoprotein E phenotype on diet-induced lowering of plasma low density lipoprotein cholesterol. J Lipid Res 35:1965-1975

31. Randle PJ, Garland PB, Hales EA, Newsholme EA (1963) The glucose fatty-acid cycle: its role in insulin sensitivity and the metabolic disturbances of diabetes mellitus. Lancet i:785-789 